\title{
Negative Impacts of Cultural Globalization on Islamic Identity: A Regional Project on Hashemite University Students
}

\author{
Fawwaz Y. Salman* \& Mohammad S. Alkhazalleh
}

The Hashemite University, Jordan

Received: 20/4/2016

Accepted: 26/6/2016

\begin{abstract}
This study aims at identifying the viewpoints of Hashemite University students regarding the negative impacts of cultural globalization on Islamic identity. The sample $(n=403)$ was from undergraduate students of Hashemite University. The total number of undergraduate students of the university is 24000 students. The study was conducted during the second semester of the academic year 2016. A researcher-made questionnaire with appropriate validity and reliability was used to collect data. The questionnaire was distributed to sample of students. The findings indicate that The Hashemite University students' viewpoints were moderate. Also, there are statistically significant differences attributed to sex and in favor of males. However, there was no statistically significant difference attributed to college.
\end{abstract}

Keywords: Cultural globalization, Islamic identity, Hashemite University.

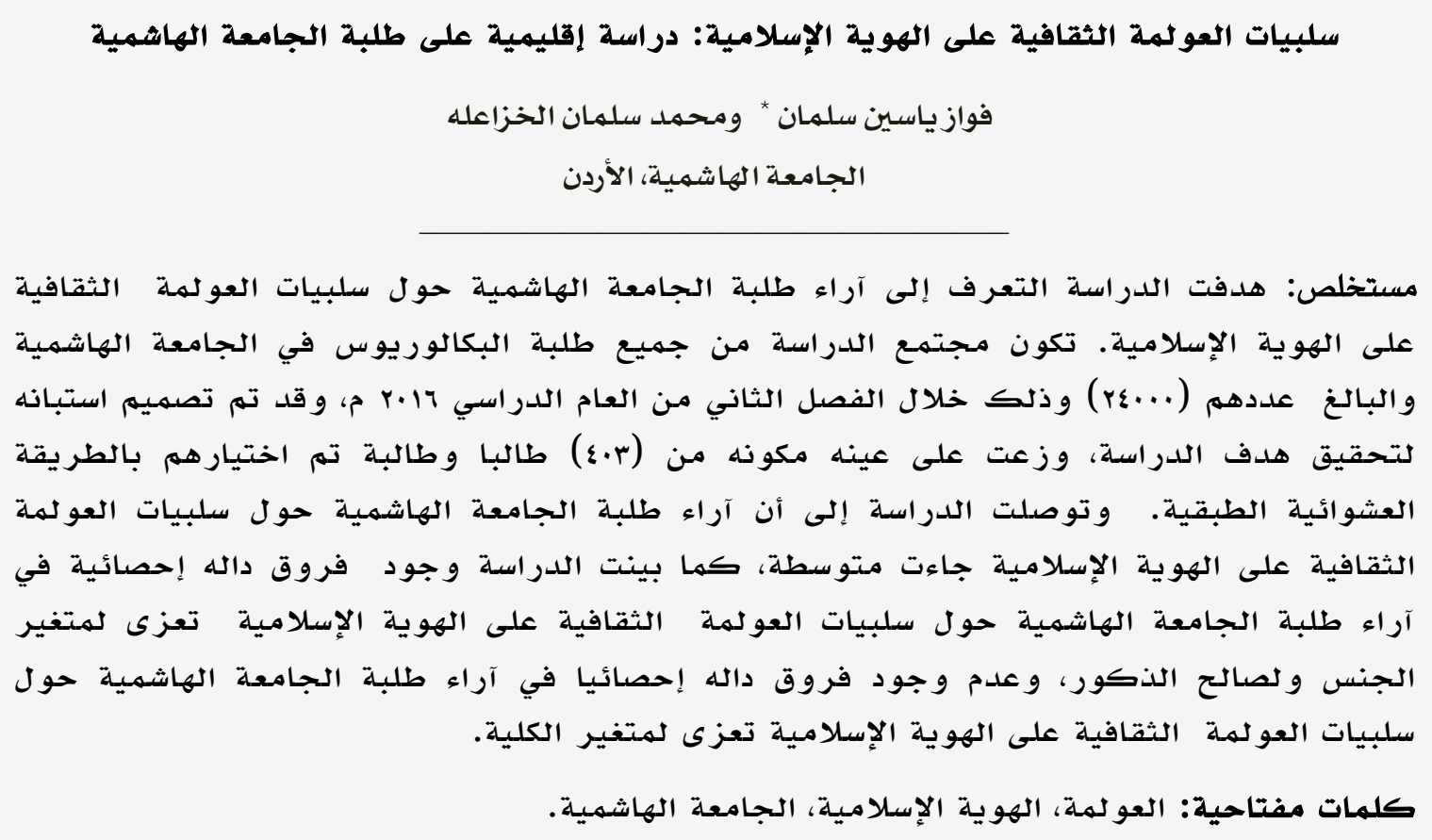

*dr.mohamadslman@yahoo.com 
Globalization according to Tahoon, (2003) is one of the most debated issues in the intellectual milieu. Scholars have been studying globalization since the first half of the last century. Due to the profound impacts of globalization and its various impacts on identity, several groups of societies around the world have interacted with this phenomenon and dealt with it from different points of view. Some societies consider globalization as a phenomenon that affects negatively identity throughout melding cultural and religious aspects and shaping cultures into Western lifestyles. Others consider globalization as a contributing factor in the process of progress and development apart from old-fashioned traditions and useless habits.

Al-Ani (2009) states that globalization is considered as another challenge amongst several challenges surrounding Islamic nations. Globalization challenges differ from other kinds of challenges in terms of quality, quantity, power, capability, hazardousness, and seriousness in achieving the desired goals that other thoughts and methods were failed. Some educators believe that the most dangerous dimension of globalization is that it strives to replace the values, principles and standards of one culture into another. This will lead to replace one culture in a place of another culture. In other words, as Zayed (2005) opined, the customs and values will be annihilated by customs and values of another culture.

Another factor to consider is that the concept of globalization is multidimensional, as there are several aspects of globalization, namely economic, social, political and moral globalization. Culture clearly affects people's minds and trends to accept other dimensions of culture. Culture is considered as the main element in the life of an individual, society, or nation. Moreover, it includes traditions, values, beliefs, lifestyles, arts, literature, and human rights (Al-Jaberi, 2000). Another comprehensive definition of culture has been provided by Balqasmi (2012), who notes that culture is the identity that represents loyal feeling towards a certain social entity which maintains social privacy, stored information, cognitive experiences, and behavioral patterns.

Cultural globalization has its means and implications. Means refer to machines, tools, technological and electronic devices. Implications, on the other hand, refer to intellectual programs, literary perceptions, artistic perceptions, doctrines, critical assumptions, ideologies, political views, lifestyles, clothing codes, foods, drinks, music programs and the like. According to Al-Tweijri (1998), cultural globalization is a civil trait, in which it needs to keep up with global development. Therefore, it is composed of contradictory components and involves elements of an aggressive spirit against the sovereignty of cultural identity of any nation. Moreover, cultural globalization slights and disregards the nation's culture. Cultural globalization tries to obligate the whole world to adopt the same political, economic, social, and cultural system. In the same vein, the world will breach God's teachings in his creation as well as being away from historical logic and natural law.

To understand cultural globalization, we must first understand that it is only a colonial policy is aiming at eradicate cultural, religious, civic, and national particularities of nations and peoples. Subsequently, suffice it to say, it threatens the Islamic identity and entity. That is actually crawling quickly into our lives. Thus, the war against Islamic identity paves the way for imposing political, military, economic, mass media and cultural domination over the Muslim world.

Some educators like Al Harethy (2001) claim that there are many negative impacts of cultural globalization. These negative impacts are as follows:

- It deepens the individuals' engagement in physical life and satisfying sensual desires. In contrast, it neglects the existence of the afterlife and despises superstition by attributing the person who believes in the existence of the afterlife by superstition and naivety.

- It breaks religious barriers by contemplating and manipulating of one's beliefs about the concepts of self, God, and the Prophet.

- It destroys the young's standing and sanctity by making them grow up with isolation from their religion as well as widening the gap between them and their heritage.

- It boosts individual's property and valuefree culture, even though if it is beyond religious constants and human limits. 
- It motivates youth's capabilities and interests toward indulging them in practicing menial hobbies like dancing and singing that have nothing to do with usefulness.

- It promotes Western culture in Muslim society. As a result, this shall represent a social deviation that is different in values, customs and traditions from Islamic society; for instance, clothes, patterns of Western food, and methods. This also shall represent a savage invasion on the patterns, styles and methods of Islamic cultural life.

Al Reqeb (2008) points out that the most important negative impacts of cultural globalization are through:

- Reducing the value of different cultures, and imposing the domination of one culture which control globalization's mechanisms and centers.

- Spreading Western taste in consumption and in practicing social behavior with others.

- Depriving developing countries from reaching advancement or progress.

- Penetrating local cultural infrastructure and intensifying the risks of alienation, invasion and cultural colonialism. Removing cultural civilized identity of Muslim nations and removing personal privacy of Muslim peoples (which are: religions, languages, histories, customs, traditions and morals).

Al-Kayed (2011) claims that the identity of any nation or people is a result of doctrines, thoughts, languages, histories, arts, literature, heritages, values, morals, customs, feelings, minds, behavior standards, and other aspects that differentiate nations, peoples and societies. Accordingly, identity is the constant fate and common essence of traits and characteristics that differentiate a certain civilization from one another.

In spite of the damaging consequences that globalization has, scholars argue that globalization is beneficial for individuals and nations. They argue that the process of globalization has positive impacts on cultural identity of technology, youth and religion as follows:
- The beneficial aspects of spreading information technology (IT) and communication worldwide. Moreover, the transitional development that happens in the cultural and scientific communication between nations, as well as the spread of cultural technology.

- The beneficial aspects of the communication role and the international media networks (including satellite channel) and the international information network (internet) in covering international and local news is to form a larger scale of understanding and analysing other cultures. As a result, this will form a huge ability to understand and analyse events, also to take apart in scientific seminars and cultural events.

- Another positive impact shown on Muslim nations that globalization enables scholars and preachers to deliver the message of Islam and Islamic culture to all people around the world. As a result, this will enable the openness of Islamic cultures to other cultures, and will also positively affect other cultures.

- Enabling Islamic intellectuals -through the international communication media- to discuss intellectual doctrines, and confront destructive philosophical movement.

- Contributing in lifting the injustice on scientifically prosecutors in Arab world -through the impact of the transmitted pictures on governments and parties- particularly as Arab people suffer from the absence of Muslim intellectuals in the sustainable development process, and the marginalization of those who are culturally and scientifically qualified.

- The last positive impact is the increase of political awareness among people to fairly impact the course of events.

In conclusion, the positive impacts of globalization on cultural identity are that global culture drives people to move forward in the way of reform and to eliminate cultural subordination in both values and habits, through using means and reasons to support the global iden- 
tity based on cooperation, bond, sense of loyalty, and non-discrimination.

Al-Kayed (2011) confirms that the identity of any nation or people is the total of faiths, thoughts, languages, histories, arts, literature, heritages, values, morals, customs, consciences, standards of mind, behaviors, and other features that distinguish nations, peoples, and communities. Identity is constant amount and common core between traits and features which distinguish one civilization from another.

Al-Ani (2009) indicates that the most important foundations of Islamic cultural identity are:

Religion or Islamic Belief: Islamic belief is considered one of the most important elements of cultural identity of the Islamic nation that brings Moslems together with various peoples and nationalities of the world.

Arabic language: Arabic language is considered a basic factor that distinguishes one culture from other cultures. It is the characteristic of one nation or one people to connect and to communicate ideas, and to prove and to confirm the identity.

History: Common history among individuals of one's nation is considered an important component that expresses the basic identity and strengthening bonds among one people.

Heritage: Heritage is the product of civilization with all of experiences and events contents.

Cultural unity: Cultural unity is the common cultural elements among the nation's people.

Common psychological configuration: Common psychological configuration includes customs, traditions, morals, feelings, sensations, holidays, weddings, dresses, and the like.

It should be noted that Islamic identity of Arab nations are being targeted clearly by influencing the children and youths. Therefore, there is a serious threat to the collective Islamic patterns of life, values, and ideologies. As it has been discussed, the main source of this threat lies in the power of globalization and prompting reformulation of the universal human values, respecting human rights, demands of new world order, common human destiny, global village, education of world peace and many other terms and contained in the contemporary globalization dictionary.

\section{Problem and questions of the study}

Scholars have claimed that there is a growing need to confront the negative impacts of cultural globalization in its various forms. For example, we should encourage a sense of pride about the identity and spread awareness of identity's characteristics, cooperate with other cultures carefully without melting by the lead of other civilizations, we should educate nation's people about the negative impacts of blind imitation on other nation, we should not accept the governance of globalization on our Islamic culture,we should not be separate from our origins and ignore our culture as this leads to become lost, finally, we should not neglect the importance of regional and international conferences to reinforce the internal front of cultural identity in order to face cultural invasion. However, on the educational level, we should work together on raising the next generations to be conscious and to be able to distinguish between what is original and what is unoriginal and deceptive aspects through curricula and basic materials adopted by educational systems. Moreover, reviewing the content of the teaching curricula and referring to religious, historical and linguistic references and resources in order to confirm Islamic cultural identity (Zago, 2010).

As a result, there is a growing need to confront the impacts of cultural globalization on cultural identity throughout the interaction between national and foreign cultures within balance limits and based on mutual respect. Besides, it is crucial to exploit technological techniques through presenting and publicizing the most important characteristic of national culture. Moreover, it is important to shift from a consumer society to a productive society.

According to the perceptions of students of Hashemite University, the researchers notice that the influence of material and utilitarian that prevail in light of globalization affected youths. As a result, this impact is clearly shown in the decisions taken by youths in which sticking to their values, beliefs, and what they grew up with in one hand, or following the new methods of life in the other hand. This conflict leads to disorder their identity and affects their behaviors and thoughts. Therefore, this study comes to examine the viewpoints of Hashemite University students 
about the negative impacts of cultural globalization on Islamic identity by answering the following questions:

First Question: What are The Hashemite University students' viewpoints about the negative impacts of cultural globalization on Islamic identity?

Second Question: Do The Hashemite University students' viewpoints about the negative impacts of cultural globalization on Islamic identity differ due to variables of sex and college?

\section{Significance of the Study}

The significance of the study comes in parallel with the importance of the topic itself. This study is considered one of the exerted efforts to monitor the most important negative impacts of cultural globalization on Islamic identity regarding to students of Hashemite University. The main purpose of this study is to establish new mechanisms that enable youths to follow and deal with globalization without threatening their principles and constants. These mechanisms will increase youths' awareness and enable them to benefit from the impacts of globalization without affecting their authenticity and privacy of their Islamic culture.

\section{Study Objectives}

The present study aims at disclosing the negative impacts of cultural globalization on the Islamic identity of Hashemite University students. The study also aims at measuring the extent of Islamic identity influenced by globalization. Finally, the study also aims at finding appropriate solutions to overwhelm the cultural impacts on Islamic identity of the Hashemite University students.

\section{Terminology of the Study}

Globalization: Bakar (2001) defines globalization as a system based on the computer and information revolution, which is based on information and unlimited technical creativity without taking into consideration to the systems, civilizations, cultures, values, and geographical and political boundaries existing in the world that is state sovereignty.

Cultural globalization: Shdood (2002) describes globalization as a process that aims to set peoples of the world in intellectual templates and with one dominance culture.
Identity: Al Tweijri (1997) defines identity as a self-specificity that distinguishes the characteristics, features, values and components of individual or society from others.

Islamic Identity: Al-Ani (2009) defines Islamic identity as including to believe in the doctrine of the Islamic nation, and to be proud of belonging to it. Moreover, Islamic identity is the adherence of one's nation and to feel the superiority, excellence, and independence in both individual and collective groups. Islamic identity is to achieve the purposes of Islam's message by calling to Islam. Islamic identity is also the totality of the historical experiences of one nation; meanwhile this nation tries to prove successful in this life.

\section{Literature Review}

Al-Amro (2012) study aims at identifying the challenges of cultural globalization and the role of Islamic education in confronting these challenges. In this study, the researcher uses the analytical descriptive method based on collecting information about this phenomenon from the previous studies and other researches in order to answer the study questions. The results show that most of the negative impacts of cultural globalization are represented in the exclusion of religion, disdaining classical Arabic language, raising the value of foreign languages, and spreading the culture of fun, entertainment, violence, and extremism. Furthermore, the results show that the role of Islamic education in confronting the challenges of cultural globalization are represented through activating the school environment, emphasizing on the role of family in facing cultural globalization and the challenges, introducing the principle of education continuity, and encouraging cooperative learning and social solidarity.

Al-Sulaihat, Alzuboon, and Jamous, (2011) investigate the awareness level of faculty members of the Jordanian Universities of the globalization phenomenon and their perceptions about globalization's reflections on cultural identity. The study is based on a questionnaire distributed on a sample consisted of (600) faculty members. The results show that the awareness of the faculty members was moderate and show that there are statistically significant differences in the level of awareness attributed to the college variable and in favor to humanity colleges. 
Al-Kayed (2011) investigates a study entitled "The role of universities in facing cultural globalization and building original and contemporary Arabic identity". The study was conducted in Al Quds Open University. The sample of the study consisted of (555) individuals. The researcher finds that the most negative impact of cultural globalization is the threatening surrounded cultural privacy. The researcher recommends a series of roles and responsibilities that universities should consider encountering cultural globalization challenges including establishing strategic plans to encounter cultural globalization challenges. In addition, teaching methods, mechanisms of teaching, and recruiting migratory scientific talents need to be reviewed.

Masadeh and Al-Shareefain (2010) conducted a study which aims to explain positive and negative impacts of cultural globalization and finding methods to deal with cultural globalization in order to reduce the negative impacts on Islamic nation. Thus, in order to achieve these objectives, the researchers use two methods: descriptive method and analytical induction method. The results show that cultural globalization affects negatively, among several effects, the Islamic identity of the nation such as: the absence of unification, infiltration of polytheism, idolatry, globalization of family, distortion of Arabic language, prejudicing civilizations humanity, and the distortion the elements of teaching process.

Al-Reqeb's (2008) study aims to identify the impacts of cultural globalization and finding methods to confront the negative impacts on Islamic nation. The study is based on an analytical descriptive method by collecting and analyzing information in order to answer the study questions. The findings of the study show that the idiomatic meaning of globalization is represented by the generalization of one pattern on other patterns. Another finding to consider are that the most important advantages of globalization on cultural identity are to simplify communication process between all peoples and nations, to spread the call of Islam, and to shorten the distances among peoples, and to technological advances. Whereas the most important negative impacts of cultural globalization on cultural identity are penetration culture, minimizing different cultures, spreading Western culture that is based on consumption, spreading im- morality, violence and atheism as well as disappearing noble values.

Kanaan (2008) conducts a study entitled "University students and cultural identity under new globalization". The study is based on a questionnaire distributed on a sample study which is consisted of all Damascus University students including the various scientific and humanitarian specialties. The study confirms that the most important problems of the university are social, economic, religious and moral problems. The reasons behind these problems are family, gender, profession, identity addiction, alienation and indifference. The researcher also identifies the source of concern and the main reasons behind are in the lack of self-confidence, poor economic conditions, and employment opportunities.

Al-Hussein Study (2001) examines students' attitudes toward the concept of globalization and the impact on cultural identity in the College of Education at the University of Damascus. The study sample consisted of (100) male and female students. The study's findings show that the impact of globalization on cultural identity was at a high level.

Through reviewing previous studies and researches, it has find that most of the studies confirm that there are profound negative impacts of cultural globalization on Islamic identity among youths as shown in Al-Amr (2012), Al-Kayed (2011), Masadeh and Al-Shareefain (2010), and Al-Hussein (2001) study. The study of Kanaan (2008) recommends that there is a need to consider the attention towards youths and provide them with the updating of time variable in order to preserve cultural identity, nation heritage, and Arabic values. Also, some studies show the necessity of adopting universities plans to encounter the challenges of cultural globalization. As mentioned in Al-Kayed's Study (2011), cultural globalization is an invasion that we must be prepared to confront due to the connection of globalization to people's progress and societies development. 


\section{Method}

In order to achieve the study's objectives, a survey descriptive approach has been used.

\section{Population and sample}

The population of the study consisted of all undergraduate students at the Hashemite University for the second semester of the academic year 2015/16 ( $\mathrm{n}=24000)$. The sample was a stratified random $(\mathrm{n}=440)$. The researchers distributed 440 questionnaires and 419 of them were returned. Sixteen were excluded because they were not probably filled. The total number, therefore, was 403 representing $17 \%$ of the population. Table 1 shows the distribution of the study sample.

Table 1

The distribution of the study sample accord-

\begin{tabular}{llrr}
\multicolumn{3}{c}{ ing demographic variables } \\
\hline Variable & \multicolumn{1}{c}{ levels } & Count & $\%$ \\
\hline \multirow{3}{*}{ Gender } & Male & 198 & $0.49 \%$ \\
Total & Female & 205 & $0.51 \%$ \\
College & & 403 & $100 \%$ \\
& Education & 157 & $0.39 \%$ \\
& Science & 124 & $0.31 \%$ \\
& Engineering & 122 & $0.30 \%$ \\
\hline Total & & 403 & $100 \%$ \\
\hline
\end{tabular}

\section{Instrument}

The researchers designed the instrument for the study in light of literature related to both globalization and cultural identity. Then the researchers made an initial questionnaire which consisted of 36 items.

In order to examine the validity of the instrument, judgment by ten professional arbitrators of the faculty members in the College of Education at the Hashemite University and the University of Jordan was sought. The researchers amended and deleted a number of items based on arbitrators' recommendations, and the final number of items reached 21 items. To ascertain instrument reliability, the researchers piloted the instrument on $27 \mathrm{stu}$ dents. After two weeks, the pilot sample was retested. The result showed that the coefficient of overall alpha reliability was 0.87. Likerttype scale was adopted:

Strongly agree (5 points) to strongly disagree (1 point). Thus, in order to check the degrees of freedom, the differences between the two extremes has been divided into (5) levels through the process that has been done by subtracting the highest limit (5) from the lowest (1) and the total equals (4).
$4 \div 5$ levels (very low, low, moderate, high, and very high) $=(0.8)$. Therefore, whereas the minimum represents one point, then, 0.8 (eight-tenths) have been added to each point according to each item. Consequently, the item weights will be as follows: (1 - 1.8, very low); (1.81- 2.6, low); (2.61 - 3.4, moderate); (3.41 4.2 , high); (4.21-5, very high).

\section{Results}

First Question: What are the Hashemite University students' viewpoints about the negative impacts of cultural globalization on Islamic identity? Arithmetic means and standard deviations were computed (see Table 2).

From Table 2, the results indicate that the mean of 2.90 was for the item" Making disorder in the cultural identities through creating one identity", whereas the minimum mean (2.40) was for the item:"The emergence of creativity crisis among youths". The findings confirm that there are negative impacts of cultural globalization on Islamic identity in terms of weakening values, focusing on imitating Western culture, dependence, and consumption. However, they believe that the negative impacts have a moderate influence due to the awareness and estimation of the risk and to achieve the benefit from the risk. The findings of this study are in consistent with the study of Al-Sulaihat, Alzuboon and Jamous (2011), which showed that the awareness of faculty members of the phenomenon of globalization was moderate. However, the findings of this study differ from those of Al-Hussein (2001), which showed that the impacts of globalization on cultural identity were in a high level.

Second Question: Do The Hashemite University students' viewpoints about the negative impacts of cultural globalization on Islamic identity differ due to sex and college? In order to answer this question, the researchers conducted two-way analysis of variance (ANOVA).

From Table 2, the results indicate that the mean of 2.90 was for the item" Making disorder in the cultural identities through creating one identity", whereas the minimum mean (2.40) was for the item:"The emergence of creativity crisis among youths". The findings confirm that there are negative impacts of cultural globalization on Islamic identity in terms of weakening values, focusing on imitating 
Western culture, dependence, and consumption. However, they believe that the negative impacts have moderate influence due to the awareness and estimation of the risk and to achieve the benefit from the risk. The findings of this study are in consistent with the study of Al-Sulaihat, Alzuboon and Jamous (2011), which showed that the awareness of faculty members of the phenomenon of globalization was moderate. However, the findings of this study differ from those of Al-Hussein (2001), which showed that the impacts of globalization on cultural identity were in a high level.

Third Question: Do The Hashemite University students' viewpoints about the negative impacts of cultural globalization on Islamic identity differ due to sex and college? In order to answer this question, the researchers conducted two-way analysis of variance (ANOVA).
According to table 3, the researchers note that there are clear differences in the means of the sampled categories. In order to examine the statistical significance of these differences, the researchers conducted two-way analysis of variance and the results are shown in Table 4 .

According to Table 4, there are statistically significant differences between genders and in favor of males. The researchers explain that males are more concerned about the negative impacts of globalization on the Islamic nation and more preserving on cultural heritage than females. Males are known to be more listen to news and follow political changes and events that females do. The results of this study differ from the study of Al-Sulaihat, Alzuboon and Jamous (2011), which show that there are statistically significant differences in the degree of awareness due to college and in favor of humanities colleges.

Table 2

Means and standard deviations of the items reported in descending order

\begin{tabular}{|c|c|c|c|c|}
\hline No. & Items & Mean & SD & Level \\
\hline 1 & Making disorder in cultural identities through creating one identity & 2.90 & 055 & Moderate \\
\hline 2 & Spreading a culture based on insularity & 2.83 & 057 & Moderate \\
\hline 3 & Spreading consumption values and dependence in all areas & 2.80 & 059 & Moderate \\
\hline 4 & Spreading decadence, depravity, sex and pleasure values & 2.77 & 066 & Moderate \\
\hline 5 & Spreading self-love and egocentrism values & 2.76 & 060 & Moderate \\
\hline 6 & Spreading material and physical values and eliminating spiritual aspect & 2.73 & 062 & Moderate \\
\hline 7 & Eliminating cultural heritage of nations & 2.70 & 070 & Moderate \\
\hline 8 & Weakening religious affiliation & 2.69 & 069 & Moderate \\
\hline 9 & Social disintegration and poor relations among the components of one society & 2.67 & 073 & Moderate \\
\hline 10 & Increasing the aspects of cultural alienation among the people of one society & 2.65 & 076 & Moderate \\
\hline 11 & Collapsing standard Arabic & 2.63 & 078 & Moderate \\
\hline 12 & Collapsing of the values of belonging and loyalty & 2.61 & 079 & Moderate \\
\hline 13 & Blind imitation of the West in all areas & 2.58 & 083 & Moderate \\
\hline 14 & Spreading the violence, extremism and excessiveness values & 2.57 & 085 & Moderate \\
\hline 15 & Spreading the personal benefit values & 2.55 & 089 & Moderate \\
\hline 16 & Cancelling the personal privacy & 2.53 & 087 & Moderate \\
\hline 17 & Generalizing a unified model of cultural behavior on others & 2.51 & 091 & Moderate \\
\hline 18 & Migrating the intellectual competencies to culturally gleaming countries & 2.50 & 093 & Moderate \\
\hline 19 & Inability of youths to achieve their ambitions & 2.45 & 094 & Moderate \\
\hline 20 & Spreading the sectarianism, racism, and tribalism & 2.44 & 097 & Moderate \\
\hline \multirow[t]{2}{*}{21} & The emergence of creativity crisis among youths & 2.40 & 098 & Moderate \\
\hline & Total & 2.63 & & Moderate \\
\hline
\end{tabular}


Table 3.

Means and standard deviations by gender and college

\begin{tabular}{lrr}
\hline Gender & Mean & Standard Deviation \\
\hline Males & 2.78 & 0.64 \\
Females & 2.53 & 0.81 \\
College & & \\
Education & 2.70 & 0.83 \\
Science & 2.67 & 0.74 \\
Engineering & 2.65 & 0.61
\end{tabular}

Table 4.

Two-way ANOVA results by gender and college

\begin{tabular}{lrrrrr}
\hline College & $\begin{array}{c}\text { Sum of } \\
\text { Squares }\end{array}$ & DF & $\begin{array}{c}\text { Mean } \\
\text { Square }\end{array}$ & $\mathrm{F}$ & $\mathrm{p}$ \\
\hline Gender & 12.384 & 1 & 12.384 & 16.601 & 0.000 \\
College & 7.517 & 2 & 3.759 & 5.038 & 0.234 \\
Error & 297.656 & 399 & 0.746 & & \\
Total & 367.412 & 403 & & & \\
Corrected & 318.5 & 402 & & & \\
Total & & & & & \\
\hline
\end{tabular}

\section{Recommendations}

In light of the study results, the researchers offer the following recommendations:

1. Reviewing the components of the teaching process to keep up with the modern world developments; and establishing an Islamic cultural strategy with clear objectives and showing universality and humanitarian aspects of Islam.

2. Paying more attention to Muslim families and reducing cultural corruption and media pollution through renewing culture and rooting individual differences.

3. Enriching nation's spiritual base through emphasizing cultural interaction, awareness of future, encouraging accessing various sciences, and explaining risks and benefits.

\section{References}

Al-Ani, K. F. (2009). Islamic identity in the time of cultural globalization. Iraq: Centre of Research and Islamic Studies.

AlHarethy, S. A. (2001). Responsibility of media at emphasizing on cultural identity. Arabic magazine.

Al-Hussein, I. (2001). University students' attitudes toward globalization concept and its reflections on cultural identity. Damascus University Journal. Syria.

AlReqeb, H. S. (2008). Cultural globalization; impacts and methods of confronting. In Con- ference of globalization and its impact on Islamic world. Jordan.

Al-Sulaihat, J. Alzuboon, M. \& Jamous, A. M. (2011). Awareness degree of faculty members at Jordanian universities of the phenomenon of globalization and their perceptions of its reflections on the cultural identity. Jordan: University of Jordan, 38.

Altweijri, A. (1997). Identity and globalization from the perspective of the right of cultural diversity. Egypt: Publication of the Islamic Organization for Education, Science and Culture.

Al-Amro, S. B. S. Al. (2012). Cultural globalization challenges and the role of Islamic education in confronting them. Um Alqura Journal of Educational and Psychological Science, $4(1)$

Al-Kayed, S. (2011). The role of universities in facing cultural globalization and building the original and contemporary Arab identity. In Conference of social responsibility of the Palestinian universities. Palestine: Al-Quds Open University.

Bakar, A. (2001). Globalization. Egypt: Arab Bureau Association.

Masadeh, I, Al-Shareefain, W. M. (2010). Cultural globalization of an Islamic educational vision. Palestine: Journal of The Islamic University, 18(1).

Salem, A. B. (2006). Will national cultures die in globalization age? Algeria: Aafaq Journal, University of Blida.

Shdood, M. (2002). Globalization; concepts, manifestations and ways of dealing. Syria: Ahaoria Library for Publishing and Distribution.

Tahoon, Z. (2003). Globalization and its stressful impacts on environments. Egypt: Arab Bureau Association.

Zago, M. (2010). The impact of globalization on cultural identity of individuals and peoples. Academic for Social and Humanity Studies, 4,

Zayed, A. (2005). Globalizing modernity and dismantling national cultures. Kuwait: Alem AlFekr for Publication and Distribution, 32. 